\title{
LA GOMERA: UNA ISLA EN MANOS DE LA GRAN PROPIEDAD TERRITORIAL ISLEÑA ${ }^{1}$
}

\author{
Luis Manuel Jerez Darias \\ Víctor Onésimo Martín Martín \\ Departamento de Geografía. Universidad de La Laguna \\ luismjd@hotmail.com, vbmartin@ull.es
}

\section{RESUMEN}

El presente artículo se plantea como un intento de sobrepasar los tradicionales argumentos que se han esbozado al hablar de la propiedad de la tierra en la isla de La Gomera. Partiendo de un minucioso análisis empírico de las fuentes catastrales, hemos sido capaces de finiquitar un discurso idealista y carente de rigor científico, el cual afirma que La Gomera ha sido un territorio de minifundio, factor causante del atraso insular. Por tanto, y al contrario de esa línea de interpretación, con este estudio demostramos que ha sido una minoría, la de los grandes propietarios, el grupo que ha concentrado históricamente el grueso de las tierras en La Gomera.

Palabras clave: La Gomera, propiedad de la tierra, minifundio, gran propiedad.

\section{ABSTRACT}

The current article is an attempt to overcome the traditional arguments which have been outlined to discuss the ownership of land on the island of La Gomera. Starting with a thorough, empirical analysis of sources from the land registry, we have been able to close an idealistic discussion which although it lacks scientific accuracy, confirms that La Gomera was a land of smallholdings, a factor which resulted in the backwardness of the island. Therefore, and contrary to this line of thought, this study demonstrates that it was a minority; the major land owners who historically controlled the major part of the land of La Gomera.

Keywords: La Gomera, land property, smallholding, large property.

Fecha de recepción: julio 2015.

Fecha de aceptación: marzo 2016.

1 Este artículo es un breve extracto de varios apartados de una dilatada investigación que he culminado con la tesis doctoral: "La Organización Territorial de La Gomera: un ejemplo de subdesarrollo", presentada en la Universidad de La Laguna el 22 de mayo de 2015 y calificada con la máxima puntación. 


\section{LOS ESTUDIOS SOBRE LA PROPIEDAD DE LA TIERRA EN ESPAÑA Y CANARIAS}

Emprender un estudio de la estructura de la propiedad de la tierra en La Gomera ha sido desde hace muchos años uno de los retos y fines de nuestra labor investigadora. Siempre lo hemos considerado como un desafío, dada la complejidad que supone abordar un análisis de este tipo a escala insular, pues los trabajos sobre esta materia para La Gomera son prácticamente inexistentes. Incluso, es complicado encontrar citas sobre la propiedad de la tierra en la isla en trabajos que abarcan la escala regional, lo que indica la dificultad de hallar datos al respecto para este espacio geográfico. Sólo las publicaciones de la profesora Díaz Padilla (1990) y de Reyes Aguilar (2002) aportan información sobre la estructura de la propiedad en la isla. El primero ofrece un laborioso estudio sobre la propiedad del Señorío insular entre los siglos XV-XVIII, mientras que el segundo se limita a un breve análisis del parcelario en unas zonas concretas del municipio de Hermigua a finales de la década de 1970. Más recientemente hemos continuado nosotros con nuevas investigaciones sobre la estructura fundiaria en la isla centrándonos en el término de San Sebastián de La Gomera (Jerez Darias, 2007, 2008, 2012).

Afortunadamente no ha sido así en otras muchas partes de Canarias y la Península, a las que varias disciplinas se han acercado históricamente al estudio de la propiedad de la tierra, siendo las ciencias sociales como la Historia, el Derecho, la Economía y la Geografía, las que más han tratado esta temática. Se trata de una materia que ha suscitado fervorosos debates (sobre todo entre los años 70-80) que desembocan en la actualidad, dado que sobre la base de los estudios de la propiedad de la tierra se ha erigido una polémica de gran calado: la de la consolidación o no del capitalismo en el campo español entre los siglos XIX y XX.

Los procesos de revolución burguesa llevados a cabo en España a lo largo del siglo XIX fueron hitos históricos no culminados que impidieron la liquidación total del sistema socioeconómico precedente. La nobleza, la aristocracia y la terratenencia semifeudal no perdieron todo el poder social, económico y político que heredaban de antes de la eclosión de esos intentos de cambio; y la denominada "nueva burguesía agraria", a la vez que ayudó a consolidar el proceso de concentración de la tierra, combinó la asalarización campesina con las antiguas formas de relación feudales. Por tanto, lo ocurrido en España no lo podemos asemejar al proceso de transformación de una sociedad feudal a otra capitalista al modo que se operó en Inglaterra, Francia o Alemania, por citar casos paradigmáticos. El modelo de capitalismo español que se fue implantando denotó una debilidad que lo distanciaba del desarrollado en Europa Occidental. En nuestro país, lo que devino fue un capitalismo atrasado, con mucha carga de inmovilidad, lastrado por la pervivencia de elementos del denominado Antiguo Régimen. Elementos de base económica (estructura de la propiedad de la tierra y relaciones de producción) que tuvieron su reflejo en la esfera social (protagonismo de la nobleza y la aristocracia, terratenientes, etc.), política (caciquismo) e ideológica (como una cultura semifeudal o el gran peso de la religión católica).

El campo español ha estado determinado hasta el día de hoy por la contraposición gran propiedad-pequeña propiedad, es decir, la fuerte concentración fundiaria en pocas manos, por un lado, frente a la enorme fragmentación en pequeñas unidades parcelarias de escasos rendimientos, por el otro. Dos caras de una moneda que ha definido el principal problema 
del agro español; a saber: el problema de la tierra. Sobre éste se ha edificado toda la amalgama de vicisitudes que ha atravesado gran parte del campo y sociedad española (pobreza, emigración, explotación de la fuerza de trabajo, existencia de relaciones de producción semifeudales, semiservidumbre, caciquismo, etc.), hasta el punto de manifestarse hoy en día en regiones como Andalucía o Extremadura, por citar las más evidentes (Martín Martín, 2006, 2007). Esa dicotomía, que nunca fue resuelta por ninguna reforma agraria (revolucionaria o institucional $)^{2}$, siempre se constituyó como un claro obstáculo a la penetración del capitalismo en el agro. Por ello, consideramos que la debilidad del capitalismo fue una realidad patente en el agro del país.

Pero el debate sigue abierto. Quienes defienden la culminación de ese proceso plantean que los antiguos grandes propietarios feudales se convirtieron poco a poco en empresarios agrícolas capitalistas, y su mano de obra dependiente y servil en jornaleros y obreros del campo. Por su parte, aquellos que niegan tal conversión hablan de la pervivencia de una gran propiedad semifeudal en el agro español que ha seguido manteniendo unos regímenes de explotación indirectos de corte precapitalistas, como el caso de la medianería ${ }^{3}$ o aparecería ${ }^{4}$ en Canarias y La Gomera en particular. Una gran propiedad que basaba su poder social, económico y político en su dominio de la tierra, de ahí la importancia de los análisis sobre su estructura y regímenes de tenencia.

Si hasta los años 60 las connotaciones de atraso del campo eran ampliamente aceptadas, tal visión comenzó a ser suplantada por la de la modernización en la siguiente década, cuando el economista Joan Martínez Alier (1968) trató de poner fin al debate con su famosa obra "La estabilidad del latifundismo", en la que subrayaba la conversión del campo meridional peninsular en capitalista. Su estela la siguieron posteriormente otros autores como Bernal (1974, 1979), Fontana (1979, 1983), García Sanz (1985), Garrabou (1985), Naredo $(1971,1996)^{5}$, los geógrafos: Mata Olmo (1987), Ocaña (1987), Domínguez Bascón (1990) y Torres Márquez (2002), con importantes análisis sobre la propiedad de la tierra, o historiadores como Herrera y González de Molina (2010), entre otros muchos. Y en Canarias esa tesis fue apoyada por académicos como Antonio Macías (1984, 1995), máximo exponente de esta corriente, y otros como Pérez García (1989), Suárez Bosa (1993), Fernando Carnero Lorenzo, Luis Gabriel Cabrera Armas, Juan Sebastián Nuez Yanes, José Ángel Rodríguez Martín, Cándido Román Cervantes o José Luis Rivero Ceballos (Rodríguez Acevedo, 2009). En el lado opuesto, los que defienden que los grandes propietarios no transformaron sus fundos en haciendas capitalistas y que permanecie-

2 No se resolvió por la vía revolucionaria, dado que la derrota de las fuerzas progresistas en la Guerra Civil devolvió las tierras a los grandes propietarios; ni tampoco por la vía demoburguesa (institucional), que apenas repartió algunos latifundios.

3 La medianería era una relación de producción semifeudal, precapitalista, basada en el pago de la renta en productos. Por lo normal, bajo este sistema la producción se repartía a la mitad (1/2), un 50\% para el propietario de la tierra y otro $50 \%$ para el productor; de ahí lo de medias. Esa partición no siempre fue equitativa, en muchas ocasiones llegó a ser de 1/3, siempre con el beneficio para el propietario, claro está.

4 Era un tipo de medianería aplicada únicamente en el cultivo del tomate.

5 Tanto Garrabou como Naredo también abrieron en los años 90 una nueva línea de negación del atraso económico con la llamada "historiografía ambiental", la cual considera que los bajos rendimientos del campo español estaban determinados por las condiciones ambientales (riqueza de los suelos, fertilización, calidad del agua, etc.) (González de Molina, 2000: 29-30). 
ron aplicando relaciones de producción semifeudales en sus explotaciones, se encuentran, entre una larga lista de investigadores, autores como Tuñón de Lara $(1974,1977)$, Pierre Vilar (1980), Sánchez Marrollo (1993), Parias (1985, 1989), Díaz del Moral (1995) o Martín Martín (2006), quien también ha realizado importantes estudios sobre la propiedad de la tierra en Canarias (1991, 2006, 2007, 2008-a, 2008-b), al igual que el historiador Rodríguez Acevedo $(2008,2009)$.

Por tanto, abordamos una materia de largo recorrido histórico dentro de las investigaciones científico-sociales de nuestro país. Una materia a la que pretendemos aportar más argumentos y material empírico que ayuden a reforzar la tesis del atraso, sabiendo de antemano que el ámbito geográfico que analizamos es muy reducido dentro de la inmensidad nacional.

\section{MARCO GEOGRÁFICO}

La Gomera es una de las siete islas que conforman el archipiélago canario. Con tan sólo $370 \mathrm{~km}^{2}$ de superficie es la segunda más pequeña del conjunto y forma parte del grupo de las islas occidentales ${ }^{6}$. Tiene un relieve quebrado, con profundos barrancos y fuertes pendientes, resultante de una incesante y prolongada acción erosiva. Todo ello favorece una variedad de situaciones ecológicas en la que participan destacadamente la litología y la orientación. Administrativamente se divide en seis municipios, los del Norte: Hermigua, Agulo y Vallehermoso (que también se despliega por la vertiente meridional); y los del Sur: Valle Gran Rey, Alajeró y San Sebastián (donde se localiza la capital de la isla).

Desde el proceso de conquista iniciado a mediados del siglo XV hasta finales del XX, la mayor parte del territorio insular fue transformado por la actividad agrícola. Desde la costa hasta la cumbre son perceptibles actualmente las huellas de ese largo proceso de antropización en el impresionante sistema de terrazas (o bancales en el leguaje local), solución recurrente que empleó el campesinado gomero para salvar la abrupta orografía insular.

Al igual que en el resto del archipiélago, en La Gomera se combinaron históricamente dos modelos agrícolas contrapuestos, pero íntimamente imbricados: el modelo tradicional o de subsistencia, y el modelo comercial o de exportación. El primero era el orientado, en su mayor parte, al autoconsumo, por lo que sólo una pequeña fracción de lo producido podía destinarse a la venta. Este tipo de agricultura era el propio del huerto familiar, del policultivo de secano y frutos menores (cereales, papas, legumbres y hortalizas) producido por los pequeños propietarios en su minifundio y por los campesinos sin tierras en régimen de medianería en las fincas de otros propietarios mayores. Geográficamente se extendió por la franja de medianías ${ }^{7}$ (zona de influencia de los vientos alisios y su aporte de humedad) y en los fondos de los barrancos y valles principales (existencia de manantiales de agua y buenos suelos). Su

6 Desde el punto de vista geográfico las Islas Canarias se dividen en islas occidentales e islas orientales. Al primer grupo pertenecen: Tenerife, La Gomera, El Hierro y La Palma; y al segundo: Gran Canaria, Fuerteventura y Lanzarote, más los islotes que conforman el Archipiélago Chinijo (La Graciosa, Montaña Clara, Roque del Este, Roque del Oeste y Alegranza) y el de Lobos. Asimismo, desde una delimitación político-administrativo a las islas occidentales constituyen la provincia de Santa Cruz de Tenerife y las orientales la de las Palmas de Gran Canaria.

7 En Canarias las medianías identifican a la franja situada entre los 500-900 metros de altitud, si bien, ese intervalo varía en función de la vertiente en la que nos encontremos. Así, en la de barlovento la zonificación podría establecerse entre los 400-900 m.a., y en la de sotavento entre los 600-1.000 m.a. 


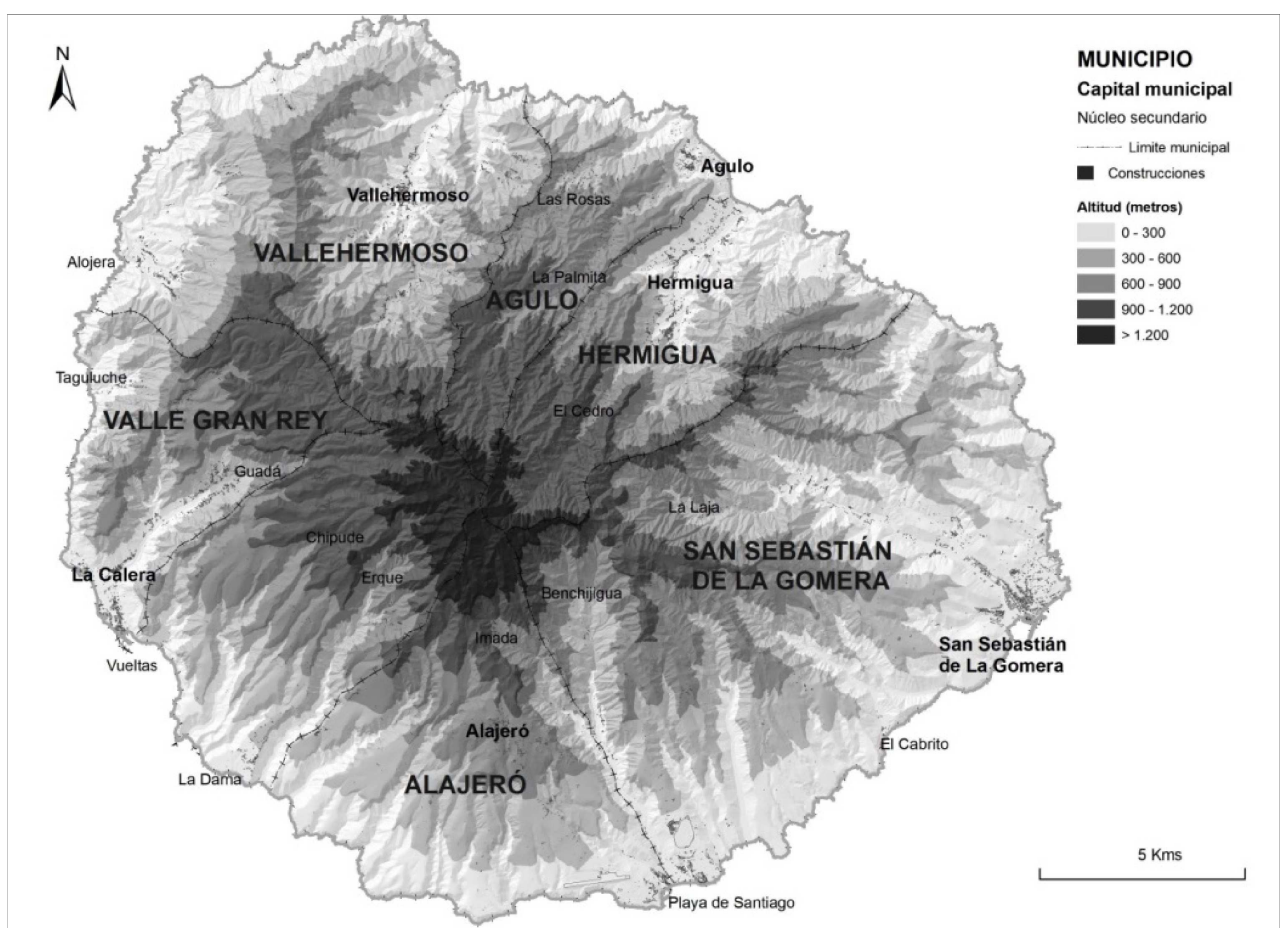

Fuente: base cartográfica de Grafcan. Elaboración propia.

minifundismo, la baja productividad y las relaciones de producción que lo sostenían (medianería) fueron los motivos principales que generaron su abandono, favoreciendo la emigración masiva iniciada en la isla a partir de los años cincuenta del siglo XX. Hoy es un tipo de agricultura que se mantiene sólo a tiempo parcial. Por su parte, el modelo comercial o de exportación siempre se sostuvo sobre los monocultivos, tanto de secano como de regadío, siendo los tomates y los plátanos los que dominaron la escena comercial a lo largo del siglo XX.

Si el modelo tradicional ha sido el vinculado con el minifundio y la medianería (que fue la relación de producción dominante dentro de este tipo de agricultura), el de exportación lo ha sido con la mediana-gran propiedad, el capital extranjero y el trabajo asalariado, si bien, en nuestra tesis hemos demostrado (en un amplio capítulo dedicado al estudio de las relaciones de producción) que el salario no terminó de sobreponerse a las relaciones semifeudales como la medianería y la aparcería en el plátano y tomate respectivamente.

Estos cultivos de exportación fueron introducidos en La Gomera por las firmas inglesas a principios de dicha centuria, inicialmente en los valles del Norte, para extenderse posteriormente por los meridionales y algunas lomadas, transformación que supuso la construcción de importantes infraestructuras hidráulicas para su riego. La intensidad y extensión de este 
tipo de agricultura en la costa sureña fue de tal grado, que marcó el inicio de una polarización socioeconómica insular que perdura en la actualidad, con unos municipios norteños estancados socioeconómicamente frente a los meridionales que concentran las principales inversiones de capital, la cuales han supuesto la sustitución de las otrora fincas agrícolas en urbanizaciones turísticas y residenciales.

\section{EL TÓPICO DEL MINIFUNDISMO EN LA GOMERA}

Calificar a La Gomera como un territorio dominado por el minifundio ha sido una constante en gran parte de los trabajos que han abordado la cuestión agraria insular, incluso, por aquellos que lo han hecho de forma tangencial. Cada vez que se afronta la temática de la propiedad de la tierra en La Gomera hay que dar por seguro que se va a hablar del poder del minifundio, de la misma forma que un devoto considera la omnipresencia de su deidad.

"El sector agrícola presenta una característica que es necesario destacar: el minifundio. Son cerca de cinco mil los propietarios agrícolas de La Gomera; hay miles y miles de minúsculos trozos de terreno cultivado desperdigados por toda la isla....en régimen de explotación familiar." (VV.AA., 1969: 23).

Por supuesto que eso no es ningún disparate, no se cae en ningún error cuando se afirma la importancia del minifundismo en La Gomera. Cuando nos acercamos al territorio insular y contemplamos las formas parcelarias se muestra claramente el predominio de las pequeñas fincas, muchas de ellas con tamaños ridículos (unidades de $12 \mathrm{o} 22 \mathrm{~m}^{2}$, por ejemplo). Cuando contemplamos los planos catastrales llegamos a la misma conclusión. Según los datos del catastro de 2001, que es el que nos ha permitido obtener estadísticas a detalle del tamaño del parcelario, el 99\% de las unidades (72.000 entre parcelas y subparcelas) son inferiores a las 5 hectáreas, iy el 54\% no llegan a los $1.000 \mathrm{~m}^{2}$ ! Pero, a nuestro parecer, esto es una primera aproximación, válida, pero incompleta, dado que no entra en el centro de la cuestión, pues: ¿y la gran propiedad? ¿No hay gran propiedad en La Gomera? ¿Es toda ella dominio del minifundio? Casi todos esos trabajos hablan del carácter minifundista insular como si sólo existiese éste, dejando en un segundo plano la otra parte que conforma la dialéctica del régimen de tenencia; esto es, la presencia de la gran propiedad. Desde nuestro punto de vista, no se puede comprender el minifundismo dejando al margen el papel de la gran propiedad, pues para que exista la una debe de existir la otra. Esta ha sido una ley histórica. En las sociedades agrarias los terratenientes repartían pequeños lotes de tierra que entregaban a los campesinos como fórmula de sujeción de la mano de obra. Esta estrategia tuvo amplio desarrollo en aquellos países en los que la revolución burguesa no llegó a término, tal y como fue el caso español. Por ese motivo fue tan evidente en La Gomera. Aquí, esa concomitancia entre la pequeña y la gran propiedad no iba a ser una excepción a lo ocurrido en buena parte de España. Era la manifestación local de lo definido por diversos autores que abordaron la cuestión agraria en el país y que denominaron como la "estabilidad del campo español"».

8 Por ejemplo, en el siguiente trabajo: Alonso V., Calzado, J., Huerta, J., Langreo, A., Viñas, J., (1976): Crisis agrarias y luchas campesinas (1970-1976). Ayuso. Madrid., se trata este aspecto. 
Pero las explicaciones dadas para nuestra isla transitaron por otros derroteros, principalmente por los del determinismo ambientalista:

"Predominaban las pequeñas explotaciones familiares, muy parceladas además por las características del relieve gomero (...)" (Burriel de Orueta, 1981: 225).

En este sentido, tal argumento sólo ha servido para velar, detrás de esas condiciones naturales, el verdadero problema de la tierra, que no es otro que la polarizada distribución de la misma, en la que una minoría ha concentrado grandes extensiones frente a una mayoría de pequeños propietarios y campesinos sin tierra. Esta dicotómica estructura de la propiedad fue la base que permitió, a su vez, que se practicasen unas relaciones de producción semifeudales por parte de los grandes propietarios hacia el campesinado minifundista y sin tierra, el cual se veía obligado a acudir como mano de obra semiservil a trabajar en las grandes fincas de aquéllos. Y es que al no producirse una reforma agraria que barriese esos vestigios anacrónicos en el campo gomero durante el periodo analizado, llevando a cabo una democratización de la tierra (el reparto), implicó la pervivencia de ese tipo de relaciones, las cuales se han prolongado hasta la actualidad, si bien sufriendo algunas modificaciones propias del avance del tiempo. Por tanto, es ahí donde se deben encontrar las causas del peso del minifundismo en La Gomera y no en aquellos argumentos deterministas-ambientales.

El campesino minifundista gomero, al que se debe añadir el que no tenía tierras, representó el grueso de la población de la isla hasta los años ochenta. Según el padrón de población de 1950, el 76\% de la población activa se dedicaba a la agricultura. Ese amplio conjunto estaba integrado por un campesinado pobre, explotado bajo un sistema de producción terrateniente, el cual sólo podía desenvolver una agricultura atrasada y de bajos rendimientos al sostenerse mediante relaciones de producción semifeudales. Tal pobreza generalizada era la expresión del problema de la tierra. La polarización del régimen de tenencia en La Gomera era la base sobre la que descansaba el atraso de la isla, dado que permitía a una minoría (grandes propietarios) someter a la mayor parte de la población, pues el medio de producción principal, la tierra, estaba en sus manos. Éste es nuestro posicionamiento, un discurso antagónico al determinista, al que consideramos como distorsionador de la causalidad del atraso de La Gomera, al atribuir ese rol al minifundio. Entienden la existencia del minifundio como solución a las adversidades ambientales y físicas del territorio insular, cuando, en realidad, la pequeña parcela es sólo la expresión de un proceso de desigual reparto de la tierra controlado históricamente por la gran propiedad, clase sobre la que debe recaer tal responsabilidad.

La presencia tan importante de la propiedad minifundista es la cara opuesta de la desmesurada concentración de la propiedad en La Gomera. Si atendemos a un análisis únicamente de las formas parcelarias es evidente que se hable del "poder" del minifundio, pero cuando entramos en un estudio más profundo, dirigiendo nuestro enfoque al sistema o grado de tenencia, el resultado nos depara otra solución; a saber que La Gomera es una isla de gran propiedad. Una gran propiedad que por su amplia concentración de tierras provocaba, en el otro lado, una extraordinaria parcelación, la cual sirviera de sustento mínimo a las numerosas familias campesinas.

Esa sería la síntesis con la que queremos poner al frente de los estudios de la propiedad en la isla el método de análisis que hace hincapié en el grado de concentración de la misma, 
Mapa 2

PARCELARIO EN LA GOMERA. AÑO 2001

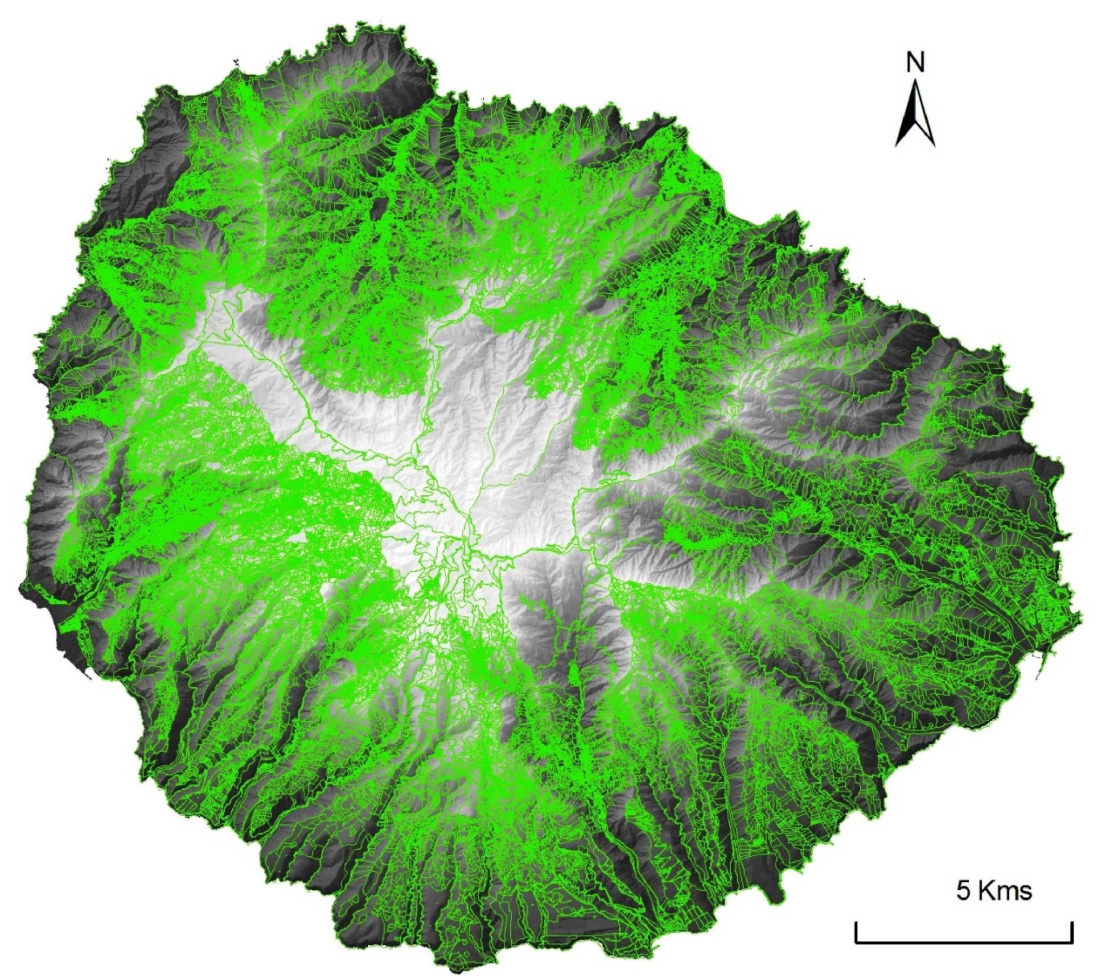

Fuente: base cartográfica de Grafcan y Catastro de Rústica de 2001. Elaboración propia.

pues sin comprender esto, no se puede entender lo otro o, por lo menos, que no se interprete de una forma unilateral y a todas luces limitada en cuanto a la forma de abordarlo. Las conclusiones que han puesto el acento en las adversidades ambientales sólo favorecen a trastocar la manera en que debería resolverse el problema de la tierra, esto es: mediante una reforma agraria que facilite el reparto y la democratización de la misma.

\section{LA GOMERA ES UNA ISLA DE GRAN PROPIEDAD}

Desde nuestra perspectiva, la típica calificación que se ha hecho -y se hace- de La Gomera como coto minifundista sólo muestra una parte -cierta- de la dialéctica de la propiedad de la tierra. Tal atribución pone el énfasis, únicamente, en el aspecto minifundista, dejando a un lado el más importante y que consideramos como el causante de ese peso tan grande del minifundismo; a saber: el dominio de la gran propiedad.

Esta cualidad no es un aspecto reciente, antes al contrario. Se trata de una realidad de amplio recorrido histórico iniciada con el proceso de Conquista abierto a finales del siglo XV 
y que se prolonga hasta la actualidad. Así lo atestigua para aquel periodo el citado trabajo de los autores Gloria Díaz Padilla y José Miguel Rodríguez Yanes (1990); y para la actualidad, nuestras investigaciones.

Efectivamente, a partir de los análisis que hemos desarrollado en los últimos años, hemos podido comprobar que la concentración de la propiedad en el siglo XX ha seguido siendo tan alta como antaño, sobre todo en los grupos de mayor tenencia. El estudio comparativo del Catastro de Rústica de los años 1957 y 2001 confirma nuestra hipótesis. Aplicando un criterio superficial para definir los distintos grupos de propietarios, hemos establecido las siguientes categorías?:

Pequeños propietarios: aquellos que poseen menos de 5 hectáreas.

Medianos propietarios: los que tienen entre 5 y 20 has., diferenciando dos subgrupos, el inferior (5-10 has.) y el superior (10-20 has.).

Grandes propietarios: con más de 20 has.

Esto nos ha permitido contrastar dos momentos históricos manteniendo un mismo criterio, cuestión que con otras variables (precios, valor contributivo, usos agrarios, etc.) se torna más compleja, debido a las lógicas y más dinámicas variaciones que sufren con el paso del tiempo. Y el resultado de la estabilidad de la gran propiedad en la isla salta a la vista con una simple tabla comparativa.

Tabla 1

NÚMERO DE PROPIETARIOS Y SUPERFICIE POR GRUPOS DE PROPIEDAD EN LA GOMERA

\begin{tabular}{c|cccc|cccc}
\hline \multirow{2}{*}{ Grupos } & \multicolumn{5}{|c|}{1957} & \multicolumn{4}{c}{2001} \\
\cline { 2 - 9 } & Propietarios & $\%$ & Hectáreas & $\%$ & Propietarios & $\%$ & Hectáreas & $\%$ \\
\hline Pequeña & 10.302 & 90,4 & 9.080 & 26,2 & 12.316 & 92,1 & 10.704 & 30,7 \\
Mediana & 908 & 8,0 & 8.109 & 23,4 & 900 & 6,7 & 7.891 & 22,6 \\
Grande & 181 & 1,6 & 17.447 & 50,4 & 162 & 1,2 & 16.299 & 46,7 \\
\hline \multicolumn{1}{c}{ Total } & 11.391 & 100 & 34.637 & 100 & 13.378 & 100 & 34.894 & 100 \\
\hline
\end{tabular}

Fuente: Catastro de Rústica de 1957 y 2001. Elaboración propia.

La superficie total de 1957 debe inducirnos a sospechar que no es correcta (causa ajena a nuestros cálculos), al ser menor que la de 2001, y es evidente que la superficie rústica se ha reducido, entre otras cosas, por el aumento del suelo urbano. Este error podría venir dado por la inexactitud de los medios técnicos empleados entonces, mucho más limitados que los utilizados en la actualidad. Por el contrario, sí creemos que en la actualidad el número de propietarios sea mayor, fundamentalmente por el efecto de las particiones por herencia, a lo que habría que añadir las ausencias de cédulas que descubrimos en los recuentos municipales para el catastro de 1957.

9 La clasificación en grupos de la propiedad territorial siempre ha sido una cuestión compleja. Para el caso canario, Román Cervantes (1997: 110) hace mención a ello, apuntando que tal inconveniente se debe a las características geográficas de las islas y al vacío de fuentes documentales al respecto. Esto ha supuesto -según el autorque la bibliografía que estudia los cambios en los grados de concentración territorial sea escasa en Canarias. 
En todo caso, como podemos ver en la tabla, la relación entre el número de propietarios y de superficie detentada es proporcionalmente inversa. Se aprecia que a mayor número de titulares, menor tenencia de tierras. La polarización del grado de concentración es tan notoria, que tan sólo menos del $2 \%$ de los propietarios (grandes) han reunido la mitad de las tierras catastradas (50\% y 47\% en 1957 y 2001 respectivamente), en contraposición a los más del $90 \%$ (pequeños) que sólo han poseído en torno a una cuarta parte de las mismas. Esto es una demostración empírica que vendría a confirmar la inmutabilidad de la gran propiedad en La Gomera. Una evidencia apoyada en datos objetivos derivados de fuentes oficiales, lo que no anula, de ninguna manera, la realidad histórica anterior carente de los mismos, pues los escasos estudios que han abordado momentos históricos precedentes, han dejado constancia que la mayor parte de la tierra en La Gomera ha estado en manos de un minoritario grupo.

Desde el siglo XV hasta el XIX la gran propiedad, con su máximo representante en el Señorío, tuvo la hegemonía de la tenencia de la tierra. En el transcurso de esa última centuria tal institución feudal desapareció, a la vez que llegaron las desamortizaciones, la supuesta liberalización de los fundos, el anhelado reparto del ingente patrimonio que estaba en manos muertas, el triunfo de la revolución burguesa, etc., etc., etc. El debate en España sobre este punto ha sido largo, enérgico y todavía se mantiene inconcluso. Al respecto, nosotros sólo podemos añadir que en el caso concreto de La Gomera, tal reparto no se materializó o, si éste se llevó a cabo, debió ser insignificante a la luz de los datos que ofrece Ojeda Quintana (1977) sobre las desamortizaciones decimonónicas, las cuales debieron seguir una tónica similar a la ocurrida en las otras islas ${ }^{10}$.

La tabla anterior parece confirmar nuestra tesis para la segunda mitad del siglo XX. En esta isla, la gran propiedad se muestra estable. Y dando un paso más, obviando el llamado "suelo público", el perteneciente a los seis ayuntamientos de la isla, vemos también que esa relación se mantiene:

Tabla 2

NÚMERO DE PROPIETARIOS PRIVADOS Y SUPERFICIE POR GRUPOS DE PROPIEDAD EN LA GOMERA

\begin{tabular}{l|cccc|cccc}
\hline \multirow{2}{*}{ Grupos } & \multicolumn{4}{|c|}{1957} & \multicolumn{3}{c}{2001} \\
\cline { 2 - 9 } & Propietarios & $\%$ & Has. & $\%$ & Propietarios & $\%$ & Has. & $\%$ \\
\hline Pequeña & 10.302 & 90,5 & 9.080 & 31,6 & 12.316 & 92,1 & 10.704 & 36,8 \\
Mediana & 908 & 8,0 & 8.109 & 28,3 & 900 & 6,7 & 7.891 & 27,1 \\
Grande & 175 & 1,5 & 11.504 & 40,1 & 156 & 1,2 & 10.520 & 36,1 \\
\hline Total & 11.385 & 100 & 28.693 & 100 & 13.372 & 100 & 29.115 & 100 \\
\hline
\end{tabular}

Fuente: Catastros de Rústica de 1957 y 2001. Elaboración propia.

10 En este sentido, Román Cervantes (1997: 117-118) también considera que en el resto del archipiélago la estructura de la gran propiedad permaneció, en términos generales, inalterable en el periodo comprendido entre la segunda mitad del XIX y primer tercio del XX. Una afirmación que da apoyatura histórica a nuestros planteamientos. 
Con esos datos poco quedaría por demostrar para afirmar el poder de la gran propiedad en La Gomera, teniendo en cuenta que, aun prescindiendo de las propiedades pertenecientes a los ayuntamientos (17\%), el resultado es el mismo: ese minoritario grupo concentrando en torno al $40 \%$ de las tierras. El desglose de los grupos de propiedad todavía lo muestra con más precisión:

Tabla 3

NÚMERO DE PROPIETARIOS Y SUPERFICIE POR GRUPOS DE TENENCIA EN LA GOMERA

\begin{tabular}{|c|c|c|c|c|c|c|c|c|c|}
\hline \multirow{2}{*}{ Grupos } & \multirow{2}{*}{$\begin{array}{l}\text { Tenencia } \\
\text { (has.) }\end{array}$} & \multicolumn{4}{|c|}{1957} & \multicolumn{4}{|c|}{2001} \\
\hline & & Propietarios & $\%$ & Has. & $\%$ & Propietarios & $\%$ & Has. & $\%$ \\
\hline \multirow{2}{*}{ Pequeña } & $<1$ & 7.348 & 64,5 & \multirow{2}{*}{9.080} & \multirow{2}{*}{26,2} & 8.655 & 64,7 & 2.443 & 7,0 \\
\hline & $1-4,9$ & 2.954 & 25,9 & & & 3.661 & 27,4 & 8.261 & 23,7 \\
\hline \multirow{2}{*}{ Mediana } & $5-9,9$ & 638 & 5,6 & 4.456 & 12,9 & 651 & 4,9 & 4.468 & 12,8 \\
\hline & $10-19,9$ & 270 & 2,4 & 3.653 & 10,5 & 249 & 1,8 & 3.423 & 9,8 \\
\hline \multirow{5}{*}{ Grande } & $20-49,9$ & 124 & 1,2 & 3.635 & 10,5 & 114 & 0,9 & 3.467 & 9,9 \\
\hline & $50-99,9$ & 34 & 0,3 & 2.343 & 6,9 & 26 & 0,2 & 1.840 & 5,2 \\
\hline & $100-499,9$ & 15 & 0,1 & 2.993 & 8,6 & 15 & 0,1 & 3.076 & 9,1 \\
\hline & $500-1000$ & 4 & 0,0 & 2.853 & 8,2 & 3 & 0,0 & 2.291 & 6,5 \\
\hline & $>1.000$ & 4 & 0,0 & 5.622 & 16,2 & 4 & 0,0 & 5.625 & 16,0 \\
\hline \multicolumn{2}{|c|}{ TOTAL } & 11.391 & 100 & 34.637 & 100 & 13.378 & 100 & 34.894 & 100 \\
\hline
\end{tabular}

Fuente: Catastros de Rústica de 1957 y 2001. Elaboración propia.

De los 11.391 propietarios totales del catastro de 1957, poco más de una veintena superaban las 100 hectáreas de dominio; pero sólo éstos concentraban algo más del 30\% de la superficie rústica insular. Dentro de este grupo se encontraban todos los ayuntamientos: Vallehermoso, Valle Gran Rey y Hermigua con más 1.000 hectáreas; Agulo y San Sebastián entre las 500 y las 1.000 has., y el de Alajeró entre las 100-200 Has. El resto eran titulares privados, entre los que había algunos privilegiados que monopolizaron la economía insular durante décadas. De hecho, en la actualidad, muchos de ellos siguen apareciendo como tales, bien bajo el mismo nombre (lo que suponemos que han de ser sus herederos) o bajo una denominación distinta. Tal es el caso de la empresa "Fred Olsen S.A.", sucesora de la antigua "Agrupación Noruega S.A.", la cual aumentó enormemente sus dominios al adquirir las propiedades del antiguo terrateniente Álvaro Rodríguez López entre los años 70 y 80 de la pasada centuria. Actualmente, esta sociedad extranjera es la mayor propietaria de la isla, con un patrimonio cercano a las 2.000 hectáreas y distribuido por diferentes municipios (Alajeró y San Sebastián ${ }^{11}$. Es el mejor ejemplo de la estabilidad de la gran propiedad territorial en la isla a partir de un reciente proceso de concentración fundiaria.

11 Una explicación más detallada del proceso de concentración fundiaria desarrollado por la actual familia Olsen se puede ver en: Jerez Darias (2012). 
Atendiendo a los datos del Catastro de Rústica de 1957 se puede apreciar con más detalle cómo se encontraba repartida la tierra en La Gomera a mediados del siglo, en un momento en el que la estructura económica insular dependía, casi en exclusividad, de la agricultura. Para ello aportamos un gráfico comparativo con el que sintetizamos cómo se estructuraba la propiedad de la tierra en cada uno de los términos municipales de la isla.

Gráfico 1

RELACIÓN ENTRE NÚMERO DE PROPIETARIOS Y SUPERFICIE CONCENTRADA SEGÚN GRUPOS DE PROPIEDAD. AÑO 1957

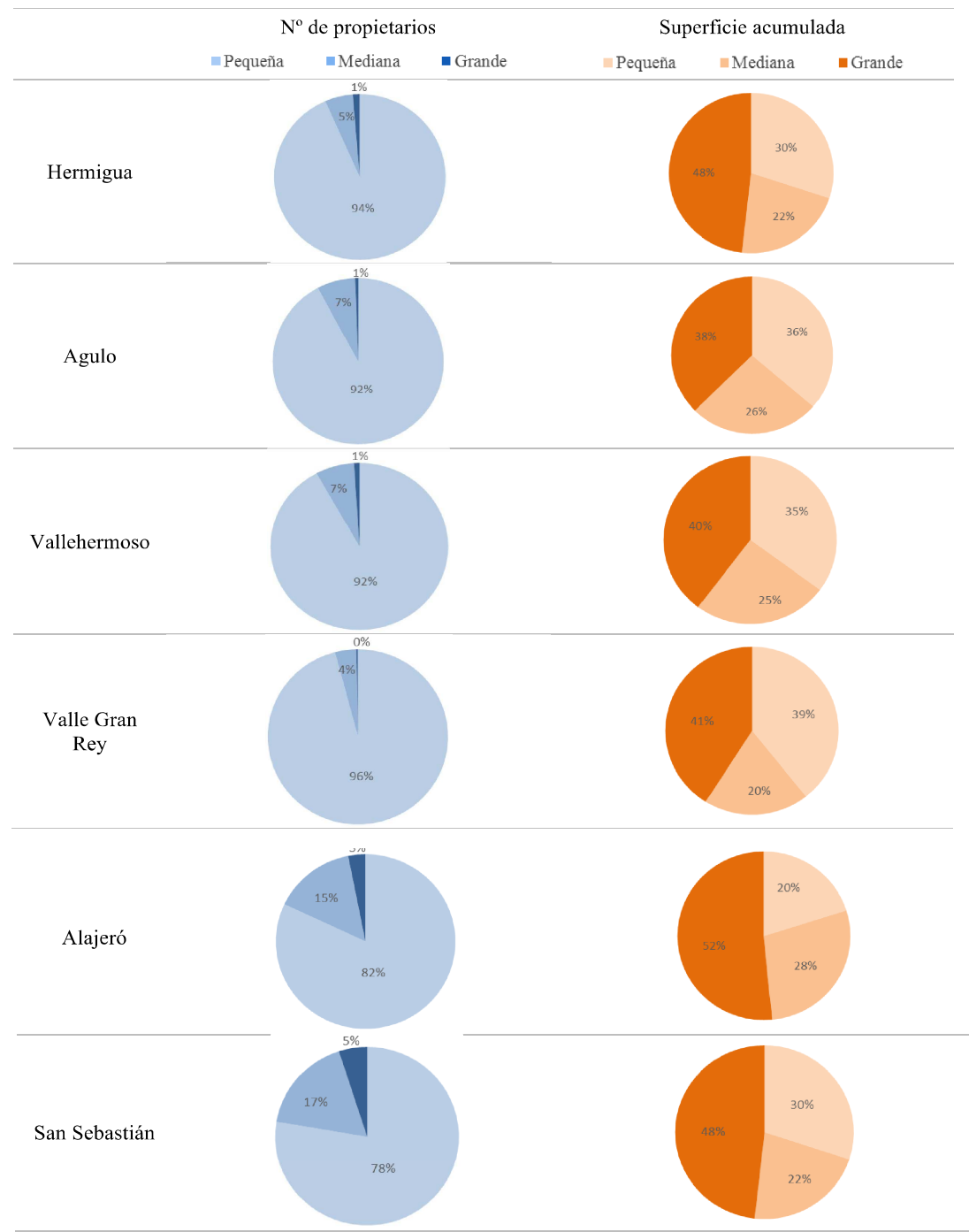

Fuente: Catastro de Rústica de 1957. Elaboración propia. 
Como se puede apreciar en cada uno de los gráficos, el grupo de los grandes propietarios era el que más tierras acaparaba, siendo, al mismo tiempo, el que menos integrantes tenía. En los municipios del Norte (Hermigua, Agulo y Vallehermoso) sólo representaba el 1\%, y en Valle Gran Rey no llegaba ni a ese porcentaje. Sólo en Alajeró y San Sebastián suponía una cuantía mayor, si bien, seguía siendo extremadamente ridícula en comparación a los de la pequeña propiedad, que era la inmensa mayoría. Esta pequeña propiedad, ampliamente representada por más del $90 \%$ de los titulares, se tenía que repartir únicamente un $20 \%$ de la superficie registrada (ver Tabla 1). Es aquí donde radica el quid de la cuestión. Por un lado, una gran propiedad que monopolizaba el grueso de la tierra frente al cuantioso grupo de los pequeños. Éstos, los pequeños, tenían que sobrevivir sobre una enmarañada trama de pobres fincas completamente insuficiente para el sustento mínimo. Multitud de familias numerosas se repartían la escasa tierra de una superficie extra-fragmentada. Sólo tenemos que fijarnos en un plano del parcelario para hacernos una idea de las condiciones que tenía que soportar esta inmensa mayoría de labradores, quienes, siendo incapaces de sostenerse con lo propio, se veían obligados a ofrecer su fuerza de trabajo en las fincas de los medianos y grandes propietarios, casi siempre en régimen de medianería.

Mapa 3

PARCELARIO EN VALLE GRAN REY (2001 Y 1957)

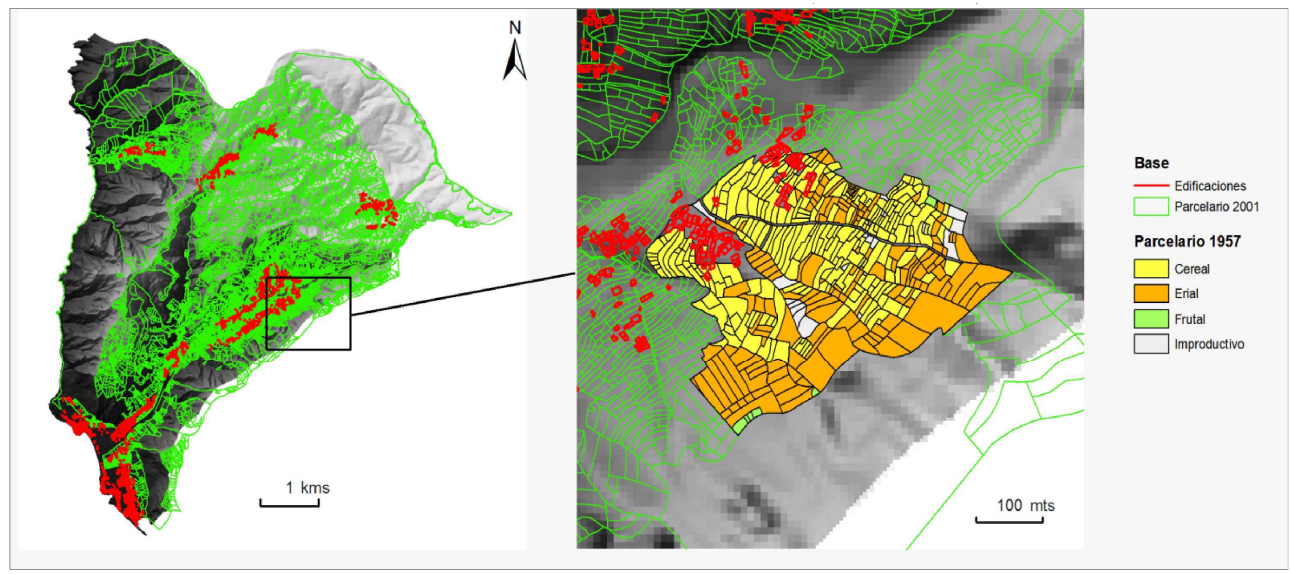

Fuente: Catastro de Rústica de 1957. Elaboración propia.

"Mi padre no tenía tierras, yo las tenía de medias. Eso funcionaba a la mitad. Se plantaba, por ejemplo, un macho de papas y si habian ocho surcos, cuatro surcos pa mí y cuatro surcos pa el amo"12.

"Todo funcionaba a medias. Pero funcionaba a medias el tomate, el millo, las papas, y el terrateniente que tenía un terreno que tenía su medianero aquí, tenía

12 Ramón Paz Paz, antiguo campesino de Alajeró. Fragmento de la entrevista realizada el 14-11-2008. 
el medianero aquí que cuidarle el cochino, cuidarle la cabra y mandarle el queso y mandarle el medio cochino cuando lo mataba y mandarle todo"13.

"Tuve animales, cabras y vacas y burros. Tierras en propiedad no, a medias. Es que aquí en Tazo tierras en propiedad no había sino los ricos. Todo el mundo trabajaba aquí a medias" 14 .

En el otro lado figuraba la abundancia, el exceso, el lujo de permitirse disponer hasta de eriales y fincas improductivas abandonadas a su suerte; la comodidad y seguridad de saber que siempre podían disponer de tierras para darlas a medias, en arriendo o venderlas.

\section{ALGUNOS DATOS SOBRE LA GRAN PROPIEDAD INSULAR}

Hasta prácticamente la década de 1980 , momento a partir del cual la estructura económica insular tornó hacia el sector servicios y actividad de la construcción, en cada municipio de La Gomera existía una serie de miembros o familias de grandes propietarios que estaba al frente de la economía y sociedad local. Atendiendo a los datos del Catastro de 1957 se puede apreciar que el grueso de ellos eran titulares locales, si bien, entre los foráneos se encontraban los mayores propietarios de la isla.

En Hermigua podemos citar, entre otros, el linaje de los Trujillo, dentro del que destacaban los hermanos Trujillo Mora, que eran los únicos que superaban las 100 hectáreas de patrimonio. Las fincas más importantes, las destinadas a la platanera (más de 2 has.), las tenían ubicadas en la mejor zona del municipio, en el lugar conocido por Santa Catalina (desembocadura del valle), donde también fijaron un taller para el empaquetado de la fruta.

En Agulo sobresalía la familia Bento, con más de 100 hectáreas repartidas entre varios herederos del antiguo patriarca Leoncio Bento ${ }^{15}$. Siguiendo un patrón común a la mayoría de los grandes propietarios del archipiélago, esta familia tenía parcelas localizadas en diferentes ámbitos geográficos, desde la costa hasta la zona de monte, lo que les permitía disponer de recursos diversos. Así, en la parte alta disponían de fincas dedicadas al plantío de secano (viñas, cereales y frutales), y en la baja tenían de regadío (plataneras, hortalizas $\mathrm{y}$ frutales). Igualmente, junto a las fincas orientadas exclusivamente al cultivo, no podemos olvidarnos de los extensos eriales que eran aprovechados por el ganado como zonas de pasto, y de los terrenos que poseían en otros municipios. Por ejemplo, en Hermigua tenían unas 14 hectáreas de plataneras situadas en el ámbito de Santa Catalina, que era el más valorado del municipio.

13 José García Jara, vecino del caserío de Alojera, municipio de Vallehermoso. Fragmento de la entrevista realizada el 22-12-2008.

14 Antonio Plasencia Sierra, vecino de Tazo, municipio de Vallehermoso. Fragmento de la entrevista realizada el 04-11-2008.

15 Leoncio Bento (1853-1937) fue la persona más influyente que tuvo este municipio en la primera mitad del siglo XX. Además de ser el mayor propietario del mismo, fue su alcalde en el período 1904-1908 y en 1927-1928. En 1921 obtuvo el acta de diputado por La Gomera dentro del Partido Liberal. Parte de su patrimonio lo adquirió en la desamortización, alguno de forma directa y, tal vez, otro por herencia. 
En el otro término norteño, Vallehermoso (aunque como hemos dicho también se despliega por la vertiente meridional), el grupo de grandes propietarios era más amplio y estaba compuesto por figuras de mayor renombre. En primer lugar aparece uno de los notables caciques del lugar: Oliver Méndez García, quien pertenecía a una de las familias terratenientes por excelencia de este municipio. Tenía un patrimonio rústico de más de 200 hectáreas repartidas en 48 parcelas. Sus propiedades estaban diseminadas por diferentes franjas de los sectores norte (valle principal) y oeste del término, lo que le permitía disponer de multitud de usos y cultivos, desde los propios de la costa (tomates y plataneras), hasta los de cumbre, con amplia cobertura de cereales, viñas y frutales en la zona intermedia y de medianías. Las fincas más importantes, las ocupadas por el tomate (casi 4 hectáreas) se localizaban en el sector occidental del municipio, en los pagos de Alojera, Tazo y Cubaba. En el primero de ellos también tenía un empaquetado de fruta.

El siguiente gran propietario de Vallehermoso era José Duque Martínez, quien tenía unas 90 hectáreas situadas en el pago de La Dama, lomada que se extiende en la vertiente meridional del municipio y a la que le dedicaremos el último apartado de este artículo como ejemplo de creación y desarrollo de una gran propiedad en La Gomera.

El caso de Valle Gran Rey fue distinto al resto de municipios, pues a pesar de la presencia de grandes propietarios, éstos eran de bajo rango. Aquí figuraba el ayuntamiento como el único titular que aglutinaba una ingente superficie (más de 1.000 has.), si bien la integraban la zona de monte y las amplias extensiones de riscos, escarpes y acantilados que dominan buena parte del término. El resto de propietarios, los titulares privados, sólo podían presumir de la posesión de algunas decenas de hectáreas de terrenos improductivos o eriales, de nada más. No tenían tierras destinadas a cultivos de importancia, es decir, a los de exportación. Ésta era una gran propiedad débil, sin fuerza, pues ninguno de sus integrantes llegó a ser protagonista destacado dentro del engranaje económico y social del municipio. Más bien fueron algunos medianos propietarios como Salvador Casanova ${ }^{16}$ los que se distinguieron por ello. Todo lo contrario a lo que ocurrió en los otros términos sureños (Alajeró, San Sebastián y sector meridional de Vallehermoso), en los que fijaron bastión los mayores propietarios que haya conocido La Gomera en su historia contemporánea.

En Alajeró el que tuvo mayor protagonismo fue Álvaro Rodríguez López, quien tenía un patrimonio superior a las 500 has., lo que suponía la mitad de lo que representaba la gran propiedad del municipio. Su patrimonio estaba repartido en 157 parcelas disgregadas por todo el término municipal, lo que le permitía un aprovechamiento múltiple y vertical desde la costa hasta la cumbre. Pero, principalmente, fue en la zona baja, en las amplias lomadas que se disponen por todo el frente litoral, donde tuvo realmente su El Dorado. Y no tanto por la superficie abarcada, pues el cereal y el erial fueron los usos que más extensión le ocuparon

16 Salvador Casanova Roldán fue un mediano propietario de Valle Gran Rey y la persona más influyente del municipio. Fue agente local de las casas agro-exportadoras británicas Jacob Ahlers y Hamilton y Cía., además de las financieras Banco Hispanoamericano y Bank of British West África Limited en los años 20 (Díaz Padilla, 2008: 40-41). Asimismo, fue uno de los exportadores más importantes del municipio (para lo que construyó un embarcadero en el núcleo de Vueltas) y tenía comercios y una factoría pesquera en la localidad. También ostentó cargos públicos en el Cabildo Insular, como consejero en 1915-1920 y 1930-1931 (Macía Armas, 2008: 479-499). Compartió durante años esas facetas empresariales con sus hijos, sobre todo con Salvador, con el que en ocasiones se suele confundir. 
(71\%), sino, porque fue ahí donde pudo desplegar los cultivos de exportación. A ello destinó las inversiones más fuertes, especialmente, a la construcción de las infraestructuras hidráulicas (canalizaciones, depósitos y presas) para el riego de los mismos.

El segundo mayor hacendado, Daniel Trujillo Mora, era vecino de la Laguna de Santiago (parte de la comarca de Playa de Santiago que pertenece a San Sebastián), aunque había nacido en 1876 en Alajeró. También tenía propiedades repartidas por todo el término (más de 200 has), las cuales sumaban un total de 204 parcelas. A excepción del polígono 18, en todos los demás poseía predios. Era un ejemplo más en La Gomera de la estrategia seguida por los grandes propietarios de Canarias del aprovechamiento múltiple vertical. En todo caso, y a la luz de los datos catastrales, suponemos que la mayor parte de lo que detentaba el señor Trujillo no le podía generar altas rentas, dado que el $60 \%$ de sus tierras eran eriales y un $23 \%$ improductivo. El resto, lo que realmente constituía el plantío, era casi todo cereal de secano (15\%). Igualmente, los demás usos en conjunto (frutales, viñas y cereal de regadío) no suponían ni el $1 \%$.

Saltándonos el orden de los mayores propietarios nos encontramos con la Agrupación Noruega S.A., a la que creemos conveniente tratar por el rol que desempeñó a nivel económico tanto en el municipio como en la isla, donde rivalizó con el omnipresente Álvaro

Mapa 4 AGRUPACIÓN NORUEGA Y DARIAS VEGUERO (1957)

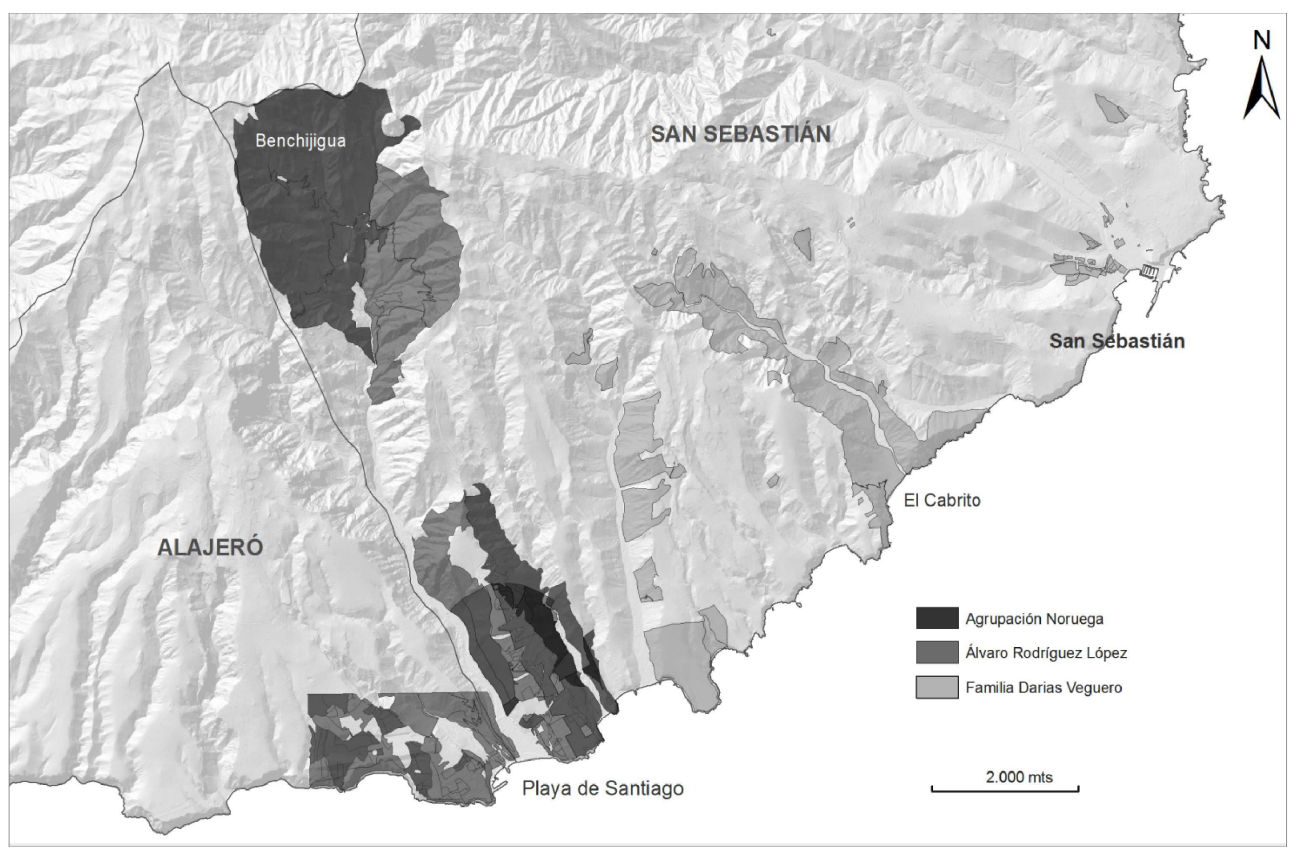

Fuente: Catastro de Rústica de 1957. Elaboración propia. (Las propiedades en Alajeró sólo son una muestra parcial, incompleta, de unos patrimonios más amplios). 
Rodríguez López. Junto a este otro gran terrateniente, la sociedad noruega fue la segunda mayor propietaria en La Gomera. En Alajeró los "noruegos" (como era costumbre denominarlos) disponían de muchos menos terrenos que aquel (83 has.), dado que la mayor parte de su patrimonio lo tenía en San Sebastián. Lo llamativo de este caso es que las tierras de cultivo ocupaban más superficie que los eriales, lo que es un aspecto discordante con el resto de grandes propietarios. Los noruegos dedicaban un $45 \%$ de la superficie al cereal de secano, mientras que un $38 \%$ eran eriales. El regadío suponía un $9 \%$ entre hortalizas y cereales.

Con el grupo anterior damos paso al municipio de San Sebastián, que era el otro donde la gran propiedad adquiría connotaciones eminentes. De los 17 grandes propietarios privados con más de 100 hectáreas que existían en toda La Gomera a mediados del pasado siglo, 9 residían en San Sebastián, ocupando, la mayor parte de ellos, los primeros puestos de esa jerarquía terrateniente. Al frente estaba el citado grupo noruego, con más de 600 has. distribuidas por toda la comarca de Playa de Santiago, espacio en el que también se localizaban las de Álvaro Rodríguez López (más de 500 has.).

Aunque ambos se introdujeron juntos a principios del siglo XX en La Gomera, al poco tiempo tomaron caminos separados. Álvaro Rodríguez López era uno de los integrantes canarios, quien, junto a otros noruegos, conformó la empresa "Sociedad Lomada de Tecina" (1909), la pionera de las sociedades que se repartieron esta zona del Sur de la isla. Posteriormente entró en escena la compañía noruega "The Norwegian Agricultura Company (Tecina) Limitada", para que más tarde se fusionaran y dieran origen a la "Comunidad de Bienes Tecina" (1924). Una vez generada esta nueva compañía se inició un complejo proceso de operaciones de compra-venta de participaciones que dio como resultado -a mediados de la centuria- la formación de dos grandes dominios: el del tinerfeño Álvaro Rodríguez López ${ }^{17}$ y el del noruego Thomas Olsen ${ }^{18}$.

La distribución de sus parcelarios abarcaba todas las franjas altitudinales, desde la costa, donde tenían las fincas más productivas (tomates, plátanos y otros frutales y hortalizas), hasta la cuenca de Benchijigua, casi en la cumbre. En esta última era donde poseían las parcelas más extensas, que eran, en su mayor parte, eriales o improductivas. Pero en torno a ellas también pusieron en producción terrenos de cereales y otros cultivos de secano que entregaban a los campesinos de la zona para explotarlos en régimen de medianería. En cambio, en la zona costera (Laguna de Santiago, Tecina y Tapahuga) predominó el regadío bajo la producción de frutas y hortalizas destinadas a la exportación.

Entre estos dos grandes propietarios aparecía con más de 500 hectáreas la familia Darias Veguero, la más distinguida de San Sebastián y con residencia en la villa capital. La mayor parte de su dominio proviene de la generación anterior, del matrimonio compuesto por Fili-

17 Falleció el 08 de agosto de 1958. Su hermano Conrado quedó como heredero de sus bienes y derechos según testamento de 09 de septiembre de 1949.

18 Su nombre completo era Thomas Olsen Fredrik (1897-1969) y pertenecía a la tercera generación de la familia Olsen, la cual fundó el grupo "Fred Olsen \& Co." en 1916. Esta empresa noruega tuvo su origen a mediados del siglo XIX, vinculada a las actividades navales.

Al disolverse la "Comunidad de Bienes Tecina" en los años 40 (aunque se mantuvo de manera simbólica hasta mediados de los 60), la figura de Thomas Olsen permaneció velada dentro de la "Agrupación Noruega S.A.", que era una sociedad integrada por antiguos miembros noruegos de la extinta comunidad. En ella Olsen era el líder y máximo accionista. 
berto Darias e Isabel Veguero Negrín. Tras el fallecimiento del marido (conocido por el "Kaiser", en alusión a su vasto patrimonio), la señora Veguero heredó todas las propiedades $^{19}$, las cuales pasaron posteriormente a sus hijos (Jerez Darias, 2007: 89-90).

Esta familia también disponía de tierras en diferentes franjas altitudinales del municipio como el resto de grandes propietarios. Sin embargo, de entre toda esa dispersión parcelaria, las propiedades más importantes se emplazaban en dos espacios muy concretos que merecen nuestra atención: la Villa capital y El Cabrito. En ambas zonas desplegaron los cultivos de exportación, principalmente, plátanos, tomates y otros frutales y cultivos de regadío. Buena parte de las huertas situadas en los mejores lugares de la capital (casco, El Lamero y La Concepción) estaban bajo su dominio, al igual que en el barranco de El Cabrito (sobre todo el tramo final), donde tenían instalada la finca más productiva, la cual medía casi 80 hectáreas.

El protagonismo de estos tres grandes propietarios no tuvo parangón en la isla. Sus dominios superaban en conjunto al de toda la pequeña propiedad del municipio, la cual estaba conformada por 1.145 integrantes. Además, el 20\% de la superficie ocupada por la platanera en todo el término municipal estaba acaparaba, casi en su totalidad, por estos tres agentes.

\section{EL PROCESO DE CONFORMACIÓN DE UNA GRAN PROPIEDAD: LA FINCA DE "LA DAMA"}

La finca de La Dama se localiza en la lomada comprendida entre los barrancos de Samarandón (al Oeste) y de La Rajita (al Este), en el sector meridional del municipio de Vallehermoso. Es la última gran plataforma (denominadas "lomadas" en La Gomera) existente al Oeste de Alajeró, pues a partir de ella nos encontramos con interfluvios de menor entidad. Diríamos que marca el límite occidental de las llamadas "bandas del Sur" de La Gomera.

En la actualidad es de los pocos espacios en la isla que mantiene una importante superficie ocupada por plataneras. Posiblemente sea, detrás de Hermigua, el lugar de mayor producción de este fruto. Y en la zona sur, junto a Valle Gran Rey y El Cabrito, es de las escasas pervivencias de un pasado agrícola basado en el regadío. Como lomada, es la única que se mantiene cultivada. En el resto sólo quedan las huellas de lo que fue una actividad intensa y representativa de la economía agraria insular contemporánea.

Los primeros datos que tenemos de La Dama se remontan a 1913, cuando el terrateniente de Agulo Leoncio Bento Casanova solicitó autorización del Gobernador Civil de la Provincia para derivar las aguas públicas de los barrancos de Erque y Erquito por medio de un canal, con el propósito de regar los terrenos de su propiedad en esta lomada. No tenemos constancia de la fecha en las que el célebre cacique adquirió sus predios en esta zona, a la que acudía con frecuencia en la época veraniega, pero debió de ser algunos años antes a la mencionada. Lo que sí podemos confirmar es que, en aquellos momentos, la finca la componían diferentes parcelas que se repartían a partes iguales este propietario y el comerciante tinerfeño (y pariente cercano) Ángel Carrillo Fragoso. Ambos compraron

19 Tras el fallecimiento de su marido Isabel Veguero fue conocida comúnmente como la "viuda de Darias". 
a 108 propietarios (la mayoría de Chipude, Agulo y Vallehermoso) casi todas las fincas emplazadas en esta lomada y las unificaron en una hacienda o granja de explotación compuesta por las siguientes parcelas:

- Terreno de aproximadamente 80 has. de regadío, con una casa de Leoncio Bento, otra para los empleados y cuatro para medianeros con un tinglado para gañanía.

- Otro trozo de tierra de $8.000 \mathrm{~m}^{2}$, también de regadío, con dos edificaciones, una de ellas igualmente para medianeros.

- Otra parcela de 3 hectáreas de regadío.

- Terreno de 10 hectáreas de usos mixtos, en la que existía un taller para el empaquetado de frutos y un tinglado para guardar materiales.

La concesión de las aguas provenientes de Erque y Erquito también la dividieron de la misma forma.

Al poco tiempo, ambos socios se separaron y Leoncio Bento vendió su parte a Ángel Carrillo por 40.000 pesetas, quien siguió explotando de forma unilateral la finca. En 1915 un cronista de un conocido periódico de Tenerife ${ }^{20}$ indicaba cómo la producción agrícola de la hacienda, integrada entonces por 140 fanegadas de "plataneras, tomates, trigo, maíz, etc.", era solicitada "con insistencia por las más importantes entidades fruteras del país y extranjeras, alcanzando precios elevadísimos, debido a sus inmejorables condiciones". Y que debido a las inversiones hechas para las mejoras de la misma (aportes de tierra, redes de riego, taller de empaquetado, etc.), la producción había aumentado de los 14.000 a los 20.000 bultos de tomates entre 1913 y 1914. Pero no mucho después, las extraordinarias previsiones que ofrecía el cronista sobre el hacendado "que de seguir las cosechas buenas unos cuantos años más lo convertirán en uno de los ricos hacendados de Canarias", se fueron desvaneciendo. En 1918 Carrillo tuvo que hipotecar ésta y otras fincas más a favor del Bank British West Africa Limited, para asegurar a éste el pago de 478.000 ptas. de la deuda que había contraído con él por diversas operaciones mercantiles. Se trataba de un banco británico de ultramar creado a finales del siglo XIX con el apoyo de la casa Elder Dempster y orientado a abrir las inversiones inglesas en las colonias africanas occidentales. Desde la primera década del siglo XX ya mantenía actividades financieras en Canarias. Especialmente en La Gomera tuvo relaciones contractuales con miembros de la gran propiedad local, como fue el caso de José Veguero Negrín, quien actuaba de corresponsal de dicha firma en San Sebastián. Aquí -como en toda Canarias- la relación entre los distinguidos grandes propietarios y el capital extranjero fue muy importante. Éstos eran, al mismo tiempo que terratenientes semifeudales, los estandartes del capital comprador local que se ponía al servicio de los intereses extranjeros en la isla.

La deuda que mantenía Ángel Carrillo con el banco inglés le empujó a venderle sus propiedades en 1921 por 150.000 ptas. Un claro ejemplo del inversor canario que, atrapado en las garras del capital extranjero (imperialista), se tuvo que desprender de todo o parte de 1915 . 
su patrimonio para saldar la deuda. Eran los años en los que el capital extranjero reanudaba la expansión de sus actividades en Canarias y las colonias una vez superada la coyuntura bélica de la I Guerra Mundial.

Esa misma entidad financiera la volvió a vender pocos años después, el 21 de noviembre de 1925, a la sociedad comercial de Liverpool -y a la que estaba unida-Elder Dempster y Compañía Limitada, por 100.000 ptas $^{21}$. La nueva propietaria, dedicada al comercio marítimo (de frutos y carbón) y agrícola, ya realizaba operaciones en La Gomera hacía más de una década. Ésta fue otra de las empresas inglesas, junto a Fyffes (con la que se fusionó en 1901 para dar origen a la Elder \& Fyffes Co. $)^{22}$, Yeoward Bros., Hamilton \& Co. o Wolfson \& Cia., que estrechó lazos económicos con nuestra isla.

Mapa 5

LOCALIZACIÓN DEL PAGO DE LADAMA

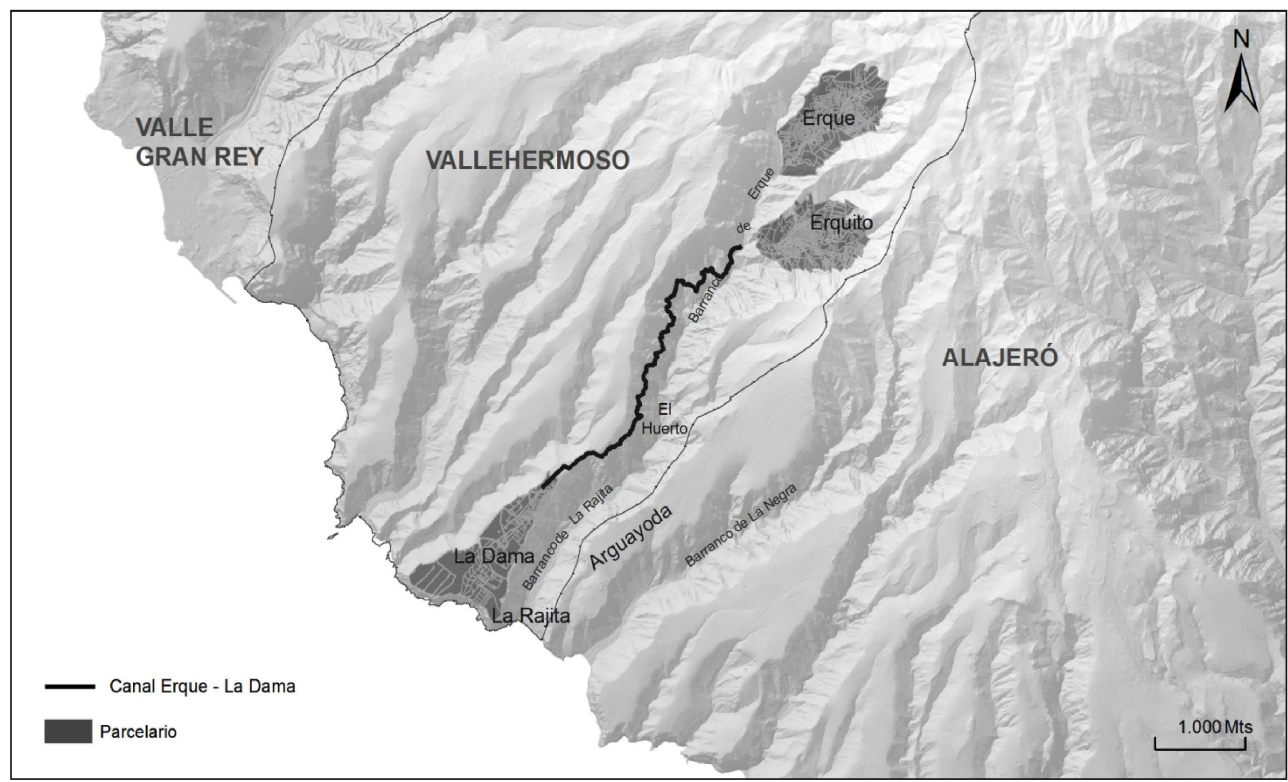

Fuente: base cartográfica de Grafcan. Elaboración propia.

Pero las circunstancias que se sucedieron en los años treinta (Gran Depresión, auge del petróleo y caída del carbón, política arancelaria británica o embargos de navieras extranjeras durante la Guerra Civil) llevaron a la casa Elder a deshacerse de muchas de sus propiedades, sobre todo en las islas menores. A partir de entonces sólo se mantuvo en Tenerife, y conservando únicamente la faceta comercializadora. Esto explica, entonces, que se desprendieran de La Dama en ese período.

21 Escrituras de la Finca 2.112 del municipio de Vallehermoso. Libro 26, tomo 100, folio 250, inscripciones $5^{\mathrm{a}}, 7^{\mathrm{a}}$ y $8^{\mathrm{a}}$. (Fondo: Archivo del Registro de la Propiedad de La Gomera).

22 Controlada en 1903 y absorbida en 1910 por la United Fruit Company (Pérez Marrero, 2000: 28). 
En 1940 la propietaria inglesa puso en venta la finca, vendiéndola un año después al comerciante palmero José Duque Martínez. Al frente de la operación mercantil se encontraba Carlos J.R. Hamilton y Monteverde, socio y gestor del grupo Hamilton y Cia., y que en aquellos momentos era el apoderado de Elder Dempster.

Duque Martínez fue un destacado miembro del capital comprador canario. Descendiente de una familia dedicada al comercio y consignataria de buques en La Palma, a principios de la década de 1930 actuaba como agente en la capital de esa isla de la Vacuun Oil Company, compañía petrolera estadounidense que recalaba en los puertos canarios con petróleo, gasolina y lubricantes para almacenar en los depósitos que tenía en ellos instalados. Sus extraordinarias relaciones con el capital extranjero también le llevaron a ejercer en 1933 los respectivos cargos de vice-cónsul y cónsul de Bélgica y de Francia en Santa Cruz de La Palma, además de agente de la famosa casa turística londinense Thos. Cook \& Son. Ltd. (antepasado de la actual transnacional Thomas Cook Group plc.) en 1936.

En La Gomera solo se asentó en La Dama. No tenemos constancia de la tenencia de otras propiedades fuera de esta zona, ni del ejercicio de actividades al margen de las relacionadas con la agricultura de exportación. Según el catastro de 1957 todas sus propiedades sumaban algo más de 90 hectáreas, repartidas en 5 parcelas que conformaban casi una unidad productiva. Los cultivos más importantes eran el tomate y el plátano (con 25 y 7 has. respectivamente), los cuales eran de muy buena calidad según refleja dicha fuente $\left(1^{\mathrm{a}}\right.$ y $2^{\mathrm{a}}$ clase). Asimismo, también dedicó 14 has. para los cereales, a pesar de que el grueso de los terrenos eran eriales ( 38 has.). Con el tiempo, el tomate fue perdiendo protagonismo a favor del plátano, y las parcelas que antes fueron ocupadas por aquella hortaliza se destinaron al cultivo de este fruto. A finales de los años setenta los miembros de la familia Duque constituyeron la "Compañía Agrícola La Dama S.A.", la cual se erigió como nueva propietaria de la hacienda. En la actualidad es la mayor finca activa de plátanos de La Gomera.

\section{CONCLUSIONES}

En este artículo hemos pretendido demostrar varias cuestiones que creemos haber conseguido:

- La explicación materialista sobre la estructura de la propiedad en La Gomera.

- El mito del minifundio.

- La Gomera es una isla de grandes propietarios.

- La estabilidad de la gran propiedad.

En contra de las tesis tradicionales (idealistas) que otorgaban a las características físicas del territorio insular la causa principal de la estructura parcelaria, nosotros declaramos que, si bien tales condiciones ambientales tuvieron un protagonismo destacado, más lo fueron las relaciones sociales que se urdieron secularmente. Con el proceso de Conquista e implantación del Señorío en la isla se dibujaron los primeros trazos de la estructura de la propiedad en La Gomera. A lo largo de varios siglos ese parcelario inicial fue sujeto de divisiones y concentraciones, de cesiones, reparticiones, ventas y compras. En el siglo XIX, desaparecido el Señorío y abiertos los procesos desamortizadores, la propiedad preexistente continuó siendo 
objeto de modificaciones, y así sucesivamente hasta la actualidad. Por tanto, los cambios en el parcelario han estado siempre presentes, nada es inmutable; ahora bien, la dialéctica que ha arrastrado en su seno la propiedad de la tierra ha estado exenta de transformación alguna. Tanto desde los inicios como hasta el tiempo presente, la contraposición gran propiedadpequeña propiedad ha persistido, y el dominio del primer grupo en la tenencia del terrazgo ha permanecido, igualmente, inmutable.

Esas mismas tesis tradicionales son las que han defendido el poder del minifundio en la isla. Los pocos estudios que han abordado o tomado de perfil la temática de la propiedad de la tierra en La Gomera, la han definido como minifundista, muy fragmentada, dividida, etc.; articulando un discurso paralelo que otorga al carácter de esas estructuras las causas de la pobreza secular del campo gomero. Cierto es que en La Gomera el peso del minifundio, de la pequeña propiedad parcelaria, ha sido tremendamente alto. El análisis del Catastro de Rústica (años 1957 y 2001) lo pone de manifiesto. Pero tal argumento es sólo una percepción, un acercamiento a lo inmediato, a lo visible a primera vista; detrás se esconde la verdadera esencia de la propiedad en la isla: el régimen de tenencia, el grado de concentración de la tierra en pocas manos.

Una cosa es atender a las estructuras en sí, al parcelario individualizado, y otra cosa bien distinta es sintetizarlo y agruparlo en función de los dueños de cada unidad. Con el primer método se desemboca en la afirmación del poder del minifundio, mientras que con el segundo se concluye en el de la gran propiedad territorial. Sin lugar a dudas, este último es el que debemos considerar primordial, dado que la tierra, ese parcelario fraccionado, tiene dueño. Y fue precisamente sobre esa contraposición entre una considerable multitud de pequeños propietarios con escasas tierras en su haber y un reducido grupo de grandes propietarios que aglutinaba la mayor parte de las mismas, sobre las que se erigieron, a lo largo de un dilatado proceso histórico, las injustas relaciones sociales que mantuvieron al campesinado gomero (con o sin tierras) sumido en la más absoluta miseria. Por tanto, este artículo se plantea como una crítica al repetido argumento del poder del minifundismo en La Gomera, el cual niega el papel fundamental de la gran propiedad como vector principal de la organización territorial de la isla.

Tanto en el análisis municipal como insular, dejamos constancia de ese hecho: menos del $2 \%$ de los titulares (grandes) reunían a mediados del siglo XX el 50\% de las tierras, mientras que más del $90 \%$ (pequeños) sólo poseían un $26 \%$ de las mismas. Son datos que, sin lugar a dudas, reafirman la estabilidad de la gran propiedad de la tierra en La Gomera. Una estabilidad que implicaba el poder de esa privilegiada minoría de hacendados frente a la miseria y la explotación de la mayoría de pequeños propietarios y campesinos sin tierras. En un espacio rural como La Gomera, el monopolio de la tierra ha sido el punto de partida para el control económico y político de la sociedad insular hasta la actualidad.

\section{BIBLIOGRAFÍA}

BURRIEL DE ORUETA, E. (1981): Canarias: población y agricultura en una sociedad dependiente. Barcelona: Oikos-Tau.

DÍAZ DEL MORAL, J. (1995): Historia de las agitaciones campesinas andaluzas. Alianza Universidad. Madrid. 
DÍAZ PADILLA, G. y RODRÍGUEZ YANES, J.M. (1990): El Señorío en Las Canarias Occidentales. La Gomera y El Hierro hasta 1700. Cabildo Insular de La Gomera y Cabildo Insular de El Hierro.

FONTANA LÁZARO, J. (1979): "Sobre revoluciones burguesas y autos de fe", Mientras Tanto, ${ }^{\circ} 1$, pp. 25-32.

FONTANA LÁZARO, J. (1983): La crisis del Antiguo Régimen, 1808-1833. Barcelona. Editorial Crítica.

GONZÁLEZ DE MOLINA, M. (2000): "De la «cuestión agraria» a la «cuestión ambiental» en la historia agraria de los noventa". Historia Agraria, $\mathrm{n}^{\circ}$ 22, 19-36.

GUIMERÁ RAVINA, A. (2008): Casa Elder. Santa Cruz de Tenerife. Mutua de Accidentes de Canarias.

HERRERA, A., GONZÁLEZ DE MOLINA, M., SOTO, D. (2010): “«El Pacto Andaluz por la Naturaleza» (1985). La confluencia del movimiento campesino y el movimiento ecologísta”. Historia Agraria, ${ }^{\circ}$ 50, pp. 121-147.

JEREZ DARIAS, L.M. (2007): San Sebastián de La Gomera: planeamiento urbano y propiedad del suelo. San Sebastián de La Gomera. Ayuntamiento de San Sebastián de La Gomera.

JEREZ DARIAS, L.M. (2008): "Las transformaciones socio-espaciales de San Sebastián de La Gomera en el siglo XX: entre la agricultura y las actividades terciarias". Papeles de Geografía, no 47-48, 101-115.

JEREZ DARIAS, L.M. (2012): "La urbanización turística de Playa de Santiago: monopolización del suelo y planeamiento a la carta". Biblio 3W. Revista Bibliográfica de Geografía y Ciencias Sociales. [En línea]. Barcelona: Universidad de Barcelona, 5 de julio de 2012, Vol. XVII, no 983. <http://www.ub.es/geocrit/b3w-983.htm>.

LÓPEZ ONTIVEROS, A. y LÓPEZ ONTIVEROS, A. (1980): "De una pequeña propiedad a un latifundio disperso: el proceso de acumulación (1940-1979)". Agricultura y Sociedad, $\mathrm{n}^{\circ} 17,133-180$.

MACÍA ARMAS, L. (2008): Historia del Cabildo Insular de La Gomera. San Sebastián de La Gomera: Excmo. Cabildo Insular de La Gomera.

MACÍAS HERNÁNDEZ, A. M. (1984): Economía y sociedad en Canarias durante el Antiguo Régimen (circa 1500-1850). Tesis Doctoral inédita, UNED, Facultad de Geografía e Historia.

MACÍAS HERNÁNDEZ, A.M. y RODRÍGUEZ MARTÍN, J.A. (1995): "La economía contemporánea, 1820-1990". En BETHENCOURT MASSIEU Antonio de (Ed.). Historia de Canarias, Tenerife.

MARTÍN MARTÍN, V.O. (1991): Agua y agricultura en Canarias: el sur de Tenerife. La Laguna: Benchomo.

MARTÍN MARTÍN, V.O. (2006): Los jornaleros hablan de la lucha por la tierra en el Sur de la España del siglo XXI. Málaga: Zambra, Baladre.

MARTÍN MARTíN, V.O. (2007): La semifeudalidad y el atraso de España. El ejemplo del Sur. Madrid: Catarata.

MARTÍN MARTÍN, V.O. (2008a): "Referencias a las supervivencias semifeudales en Canarias entre 1940 y 1970 en los estudios de Ciencias Sociales". Coloquio de Historia Canario-Americana, XVII (2006), pp. 114-132. Las Palmas de Gran Canaria. 
MARTÍN MARTÍN, V.O. (2008b): "Los jornaleros y la gran propiedad agraria en el Sur de España". Anales de Geografia de la Universidad Complutense, 28 (2), 137-165.

MILLARES CANTERO, A. (1977): "Sobre la gran propiedad en las Canarias orientales (Para una tipificación de la terratenencia contemporánea)". En MILLARES TORRES: Historia general de las Islas Canarias. Las Palmas de Gran Canaria. T.V., 257-291.

NAREDO, J.M. (1971): La evolución de la agricultura en España. Desarrollo capitalista y crisis de las formas de producción tradicionales. Estela. Barcelona.

NAREDO, J.M. (1996): La evolución de la agricultura en España (1940-1990). Granada. Universidad de Granada.

NUEZ YÁNES, J. (2005): El mercado mundial de plátanos y las empresas productoras en Canarias, 1870-2000. La Laguna. Instituto de Estudios Canarios.

OJEDA QUINTANA, J.J. (1977): La Desamortización en Canarias (1836-1855). Las Palmas de Gran Canaria. CIES. Caja Insular de Ahorros de Gran Canaria.

PARIAS SAINZ DE ROZAS, M. (1985): "La transmisión de tierras dadas a censo por los municipios en el siglo XIX". Actas del III Coloquio de Historia de Andalucía. Historia Contemporánea. Córdoba, 73-98.

PARIAS SAINZ DE ROZAS, M. (1989): El mercado de la tierra sevillana en el siglo XIX. Universidad de Sevilla. Sevilla.

PERERA LÓPEZ, J. (2005): La toponimia de La Gomera. Un estudio sobre los nombres de lugar, las voces indígenas y los nombres de plantas, animales y hongos de La Gomera (Vol. Tomo II). La Gomera. AIDER La Gomera Ed.

PÉREZ GARCÍA, J.M. (1989): La situación política y social en las Canarias Orientales durante la etapa isabelina. Las Palmas de Gran Canaria: Real Sociedad Económica de Amigos del País Las Palmas de Gran Canaria.

PÉREZ MARRERO, L. (2000): El plátano canario en el contexto internacional, su historia agrocomercial. Islas Canarias. Aspocran.

PLATA SUÁREZ, J. (1991): La comarca de Playa de Santiago en la isla de La Gomera. Transformaciones espaciales a lo largo del siglo XX. San Sebastián de La Gomera. Cabildo Insular de La Gomera.

REYES AGUILAR, A. (2002): Estructura agraria, grupos de parentesco y politica local en Hermigua (Gomera): un estudio antropológico (1900-1980). San Sebastián de La Gomera. Cabildo Insular de La Gomera.

RODRÍGUEZ ACEVEDO, J.M. (2008): "La pervivencia parcial del sistema de propiedad feudal en la España contemporánea: la enfitéusis en Tenerife". Hispania Nova, 8.

RODRÍGUEZ ACEVEDO, J.M. (2009): Caciquismo y cuestión agraria en Tenerife (18901936) (Vol. II). Santa Cruz de Tenerife: Idea.

ROMÁN CERVANTES, C. (1996): "Estructura de la gran propiedad de la tierra en el archipiélago canario: una valoración del Registro de la Propiedad Expropiable de 1933". Estudios Canarios. Anuario del Instituto de Estudios Canarios, $\mathrm{n}^{\circ}$ 41, 99-118.

SÁNCHEZ MARROYO, F. (1993): Dehesas y Terratenientes en Extremadura. La propiedad de la tierra en la provincia de Cáceres en los siglos XIX y XX. Asamblea de Extremadura. Villanueva de la Serena. 
SUÁREZ BOSA, M. (1993): Los trabajadores en las Canarias orientales durante el período de entreguerras (estudio económico y social de Gran Canaria, Lanzarote y Fuerteventura). Tesis Doctoral, Universidad de La Laguna.

TUÑÓN DE LARA, M. (1974): La España del siglo XIX. Barcelona. Laia.

TUÑÓN DE LARA, M. (1977): "Modo de producción y clases sociales en la España contemporánea”. En BLÁZQUEZ, J. M. et al.: Clases y conflictos sociales en la historia. Madrid. Cátedra, 115-135.

VILAR, P. (1980): Historia de España. Barcelona. Crítica.

VV.AA. (1969): La Gomera 69. S/C de Tenerife. Departamento de Acción Política Local de la Jefatura Provincial del Movimiento de S/C de Tenerife y Jefatura Insular de La Gomera. 